\title{
Effectiveness and perceptions of physical activity interventions in previously active women during pregnancy and postpartum: a mixed-methods systematic review.
}

\author{
Murali Krishnan Perumbakkam Subramanian ${ }^{1}$, Louise Hayes ${ }^{2}$, Peter Van der Graaf ${ }^{1}$, and \\ Liane Azevedo ${ }^{3}$ \\ ${ }^{1}$ Teesside University \\ ${ }^{2}$ Newcastle University \\ ${ }^{3}$ University of Huddersfield
}

May 6, 2020

\begin{abstract}
Background: Physical activity (PA) reduces significantly in active women during pregnancy and in postpartum. Objectives: To synthesise the evidence on the effectiveness of PA interventions delivered to active pregnant and postpartum women and to explore the perceptions of active women on being active during pregnancy. Search Strategy: Five databases were searched from inception up until 12th of May 2019. Selection Criteria: We included studies where a PA intervention was used to promote or prevent decline in PA levels in active pregnant and/or postpartum women, and either PA outcomes or participants' views on physical activity were reported. Data Collection and Analysis: Data were extracted using structured data extraction forms. A narrative synthesis of quantitative and qualitative data was produced. Main Results: Three studies with a total of 2,1426 participants were included. Quantitative studies used face-to-face sessions, goal setting, and multimedia provision to exercise at home as interventions. Different methods were used to assess change in PA with both studies reporting significant positive changes in physical activity. Qualitative data suggested that already active women are enthusiastic about continuing PA during and after pregnancy. They see health benefits and empowerment as an enabler and overcoming peer judgement and stereotypes as a barrier. Conclusion: Available evidence shows that PA interventions in already active women tend to be successful in increasing physical activity levels and foster a positive perception. These findings should inform the design and delivery of successful PA interventions in already active pregnant and postpartum women. Keywords: Physical activity; Already active; Pregnant; Postpartum.
\end{abstract}

\section{INTRODUCTION}

Irrespective of the various physical and mental health benefits that physical activity (PA) offers, ${ }^{1-3}$ and research showing that increasing population-level PA would reduce the substantial global burden of noncommunicable diseases associated with physical inactivity, ${ }^{4}$ people tend to discontinue regular exercise for various reasons. These include a change in household and residential environment, starting higher education and changing jobs. ${ }^{5}$ Notably, during pregnancy and postpartum, PA brings a range of health benefits from improving maternal glucose levels to supporting healthy neonatal birth weight. ${ }^{6,7}$ Other health benefits of PA during pregnancy and postpartum are reducing the risk of preeclampsia and preterm delivery, ${ }^{8-10}$ reducing the duration of labour, ${ }^{11}$ lower gestational weight gain, ${ }^{12,13}$ and better mental health including a reduction in depressive symptoms. ${ }^{14}$

Nonetheless, pregnancy and postpartum brings challenges to women, as various somatic, psychological, social and behavioural changes take place, ${ }^{15,16}$ which might result in the reduction of activity levels. ${ }^{17-20}$ This is 
supported by the UK statistics for PA, which suggest that only half of all adult women in the UK meet the recommended guidelines for exercise and activity. ${ }^{21}$ More specifically, studies reveal that pregnant and postpartum women only engage in 12 mins/day of moderate PA and spend around $57.1 \%$ of their time in sedentary behaviour. ${ }^{18,22}$ Various longitudinal and cross-sectional studies have observed that women with an active lifestyle before pregnancy reduce their activity levels while pregnant, and the reduction in activity continues through the postpartum period. ${ }^{17,23-27}$

Several studies have been carried out using PA, alone or in combination with other interventions, to increase activity levels in pregnant and postpartum women, typically with the aim of positively impacting on outcomes such as reducing gestational weight gain, improving mood and increasing the risk of gestational diabetes. ${ }^{28-33}$ Many of these studies employed behaviour change techniques such as feedback and monitoring, comparison of behaviour, repetition and substitution, goals and planning and social support, to reduce the decline in activity levels during pregnancy and postpartum. ${ }^{28,34-36}$ On the whole, these interventions were successful in increasing PA or limiting the decline in PA among the intervention participants compared to the control group. ${ }^{28,34-36}$

Although individually tailored exercise interventions appear to increase activity levels among pregnant and postpartum women, ${ }^{27,37}$ most of these interventions during pregnancy and postpartum focus on specific populations such as inactive women, ${ }^{38,39}$ obese women ${ }^{29,34}$ or women at risk of gestational diabetes mellitus. ${ }^{7,12,28,31,36,40}$ Existing systematic reviews include only studies of inactive women, obese women or women with other medical conditions, ${ }^{40-42}$ and no review exist on already active women. Therefore, reviewing the literature systematically for interventions on already active women is essential to provide evidence of the effectiveness of the interventions and components, other than understating women's perceptions to help to reduce the decrease of PA observed during pregnancy and postpartum.

Therefore, the aim of this systematic review was to assess the effectiveness of PA interventions that aimed to maintain or increase PA levels during pregnancy and postpartum in women who were physically active at the beginning of their pregnancy. The review also aimed to explore the perceptions of active women of being active during pregnancy. This information will help to inform the design of PA interventions for this population.

\section{METHODS}

This systematic review was conducted using the methodological approaches defined in the Joanna Briggs Institute (JBI) reviewers' manual ${ }^{43}$ and is reported using the Preferred Reporting Items for Systematic Reviews and Meta-Analyses (PRISMA) criteria. ${ }^{44}$ Details of the protocol for this systematic review were registered on PROSPERO (reg. no. CRD42019119375). ${ }^{45}$

\section{Study Inclusion and Exclusion Criteria}

Quantitative studies were included in this review only if they included a PA intervention in pregnant and/or postpartum women. Women taking part in the study must be physically active. Physical activity data at baseline were examined, to explore if on average women taking part in the study meet the UK physical activity guidelines recommendation (150 min of moderate to vigorous physical activity (MVPA) per week or 75 minutes of vigorous exercise per week). ${ }^{46}$ If this information was not provided directly (e.g. daily MVPA, Metabolic Equivalent of Task (MET)) the main author (MS) examined the data provided in the study to establish if the participants included in the study meet the PA guidelines. To be included in the systematic review, studies must report changes in PA reported either using objective (e.g. accelerometers and pedometers) or subjective (e.g. questionnaires) measurements. Qualitative studies included in the review must have included active participants (as defined by the author of the included study) and must have reported qualitative findings such as attitudes, beliefs, barriers and facilitators for PA during pregnancy/postpartum period. Studies were excluded if they included active pregnant or postpartum women who were diagnosed with any medical condition that limited their ability to be physically active. Case-studies, expert opinions or reviews and study protocols were also excluded. 


\section{Search Strategy}

A three-step search strategy was used in this review. An initial scoping search of MEDLINE was undertaken to identify studies that met the inclusion criteria. Secondly, an analysis of the text words contained in the title and abstract and the index words (subject terms and subject headings) of the identified studies and articles was conducted. A second search was then performed using all the keywords and index terms identified across all included databases (MEDLINE and EMBASE using the Ovid platform; CINAHL and SPORTDiscus using the EBSCO host platform, Cochrane Library and Web of Science). See Appendix S1 for the MEDLINE search strategy example. Finally, the reference list of all of the included studies was searched for additional studies that may not have been identified by the electronic searches.

All identified records were uploaded into EndNote X8.2 2018 (Clarivate Analytics, PA, USA) and duplicates were removed. One reviewer from the team (MS) performed the entire title and abstract screening, while two second reviewers (LA, LH) randomly screened $40 \%$ of the titles and abstracts. Two independent reviewers (MS, LA) performed the full-text screening of articles selected for inclusion based on congruence with the inclusion criteria. Any discrepancies that occurred between the two reviewers were resolved by discussions, and if required, a third reviewer $(\mathrm{LH})$ was consulted.

Quality Appraisal

The methodological quality of the included studies was assessed using the standard critical appraisal tools available from JBI. ${ }^{47,48}$ Two independent reviewers (MS, LA) assessed the quality of the studies selected for inclusion. The items were weighted equally (yes-1; unclear/no/not applicable-0). Each study received a score based on which they were rated as "good", "fair" or "poor" quality. As cut-offs for the quality assessment of the findings are not available for the JBI critical appraisal tools, the weighting is based on the predetermined cut-offs as suggested by Nordbø et al. : i) poor - if $50 \%$ or fewer of the items were not fulfilled (marked NO), ii) fair - if $51-85 \%$ of the items were not fulfilled and iii) good - if more than $85 \%$ of the items were not fulfilled..$^{49}$

\section{Data Extraction}

Both quantitative and qualitative data from the included studies were extracted into purpose-designed, pre-piloted data extraction forms which were guided by the standardised data extraction template available from JBI (quantitative - MAStARI data extraction instrument; qualitative JBIQARI data extraction instrument). ${ }^{50}$ Data extraction was completed by one review author (MS) and verified by a second reviewer (LA). The reviewers extracted the following data: study reference information (author, year, country), study participant characteristics (sample size, socio-economic status, and PA levels), study methods (e.g. theoretical approach, data collection, sampling and recruitment strategy), intervention (type, duration, intensity, delivery setting, delivery personnel) and outcomes (change in PA reported objectively or by self-report between the intervention and control group; themes related to attitudes, experiences and barriers and facilitators, types and components of interventions).

\section{Data Synthesis}

As outlined in the JBI approach to mixed-methods systematic review ${ }^{51}$ a segregated approach was used to present the results. The findings from the included studies were narratively synthesised along with tables to facilitate data7 presentation where appropriate. Main characteristics of the eligible studies such as the intervention, participant characteristics, outcome measures and the main findings were presented in tables. Results were presented as mean and standard deviation or median and interquartile range. Meta-analysis was not carried out due to the limited number of included studies and the heterogeneity of the physical activity outcomes. Findings from the qualitative study were narratively synthesised.

\section{RESULTS}

An extensive search of the included databases and deduplication resulted in a total of 7,631 unique records, of which 131 studies were included for full text screening. After full text screening, three studies were eligible for 
inclusion in the review: two RCTs ${ }^{52,53}$ and one qualitative study. ${ }^{54}$ Figure 1 presents the PRISMA flowchart for the study selection and inclusion process. ${ }^{44}$

Of the two RCTs, one was from the $\mathrm{UK}^{52}$ and one from Ireland. ${ }^{53}$ The qualitative study was performed in the USA. ${ }^{54}$ Overall, 2,142 participants were included in the studies. Both RCTs ${ }^{52,53}$ included only pregnant women in the trials, while the qualitative study ${ }^{54}$ was conducted among active postpartum women. The $\mathrm{RCTs}^{52,53}$ provided pre-pregnancy PA levels in the form of weekly MVPA minutes, weekly METs, and weekly walking minutes. The qualitative study ${ }^{54}$ stated that all the study participants performed a minimum of 6 months of CrossFit training during pregnancy. Participant characteristics from the included studies are shown in Table 1, and a description of the included studies can be seen in Table 2 .

\section{Quantitative Findings}

\section{Outcome Measures}

Different outcome measures were reported across the two included RCTs. ${ }^{52,53}$ One reported the median difference in METs, walking and MVPA ${ }^{52}$ while the other ${ }^{53}$ reported the mean difference in METs between the intervention and control group. One study showed a significant increase in METs in the intervention group compared to control $(p=0.001) .{ }^{53}$ The other $\mathrm{RCT}^{52}$ reported median differences between intervention and control group, of which weekly METs and walking significantly improved in the intervention group compared to control ( $p=0.001$ and $p=0.001$ respectively). However, no significant differences were noted for MVPA between groups. (See Table 2)

\section{Type of Interventions}

One of the RCT, used regular face-to-face sessions to deliver the intervention, ${ }^{52}$ while the other had a single face-to-face session at the beginning of the intervention followed by providing the participants a mobile app. ${ }^{53}$ The mode of activity included: supervised treadmill walking, ${ }^{52}$ providing DVD containing exercise videos ${ }^{52}$ pedometers as motivational tools, ${ }^{52}$ consultations with a health professional for goal setting and periodic reviewing, ${ }^{52,53}$ and finally mobile app and email notifications with tips for exercise and diet. ${ }^{53}$ The interventions' duration varied and were delivered across eight sessions over 8 weeks ${ }^{52}$ in a hospital setting in one of the trials. In another ${ }^{53}$ a mobile application intervention ${ }^{53}$ had only one initial face-to-face session followed by sessions to obtain data at 28 and 34 weeks of gestation.

\section{Qualitative Findings}

The only qualitative study ${ }^{54}$ included in the review conducted interviews among 22 active women who were in the postpartum period. The study aimed to examine pregnant women experiences on high-intensity PA. The interviews were analysed using thematic content analysis. Seven themes emerged exploring the experiences of pregnant women who participated in CrossFit training while pregnant - (a)quitting was not an option, (b)support and community, (c)overcoming judgments and stereotypes, (d)listening to my body \& modifying movements, (e)empowerment and pride (f)easy pregnancy and delivery, and (g)lifestyle and functioning postbaby. The study concluded that participating in CrossFit training during pregnancy provided the participants with the "confidence and ability to 1) have an active and healthy pregnancy, 2) have a natural childbirth experience, and 3) return back to their normal PA regimens and pre-pregnancy weight".

\section{Methodological Quality}

All the three included studies ${ }^{52-54}$ were appraised for methodological quality using the JBI critical appraisal tools for $\mathrm{RCT}^{48}$ and qualitative studies ${ }^{47}$ (Appendix S2 \& S3). All the studies were of fair quality (See Appendix S4). Both the RCTs followed randomisation and concealed allocation (Q1,2,3), however, due to the nature of the intervention, neither the participants nor the researchers were able to be blinded to intervention assignment $(\mathrm{Q} 4,5,6)$. In the qualitative study, the researchers did not address the influence of the researcher on the research or vice- versa (Q7) leading to a potential researcher bias in the study.

\section{DISCUSSION}




\section{Main Findings}

There is limited evidence on interventions to promote PA among already active pregnant and postpartum women and the perception of PA in this population. However, the evidence available shows that largely PA interventions are successful in increasing activity levels, and active women consider it to be beneficial to be active during and after pregnancy. From the limited information available, it is evident that simple techniques such as supervised walking, providing DVDs with exercises to do at home, provision of pedometers and goal setting and periodic face-to-face sessions for monitoring are successful to an extent in increasing the activity levels. The qualitative evidence available from postpartum women shows that already active women are enthusiastic about continuing their pre-pregnancy activity levels through pregnancy and postpartum. They also consider that PA during pregnancy empowers them with various benefits such as healthy pregnancy, having a natural childbirth experience, and returning to their normal PA activities and pre-pregnancy weight after delivery. They also consider peer judgments and stereotyping as barriers to their activity during pregnancy.

\section{Strengths and Limitations}

This study used a robust search strategy across multiple relevant databases to ensure all relevant publications were identified. It also included studies that were of at least fair methodological quality, thereby synthesising the best available evidence.

However, there were important limitations. Only a few studies were eligible for inclusion providing limited evidence. Also, due to the limited number of studies and the heterogeneous outcomes reported in the studies, a meta-analysis was not possible. Equally, although all women were active, the PA level of women involved in the study varied, reflecting a heterogeneous population in this respect. Another significant limitation in the systematic review is that, due to the different nature between the quantitative and qualitative studies included, the findings from the studies could not be aggregated, and therefore a segregated analysis was performed instead.

\section{Interpretation}

The most common behaviour change technique used in the studies included in this review ${ }^{52,53}$ is individualised goal setting and planning. There is evidence from a systematic review that the most effective behavioural technique for changing PA is goal setting. ${ }^{55}$ Also, the NICE guidelines to increase PA suggests that clinicians should use a "person-centred approach, recognising an individual's needs and motivations and agreeing goals with them". ${ }^{56}$ Out of the two included RCTs in the review, one included both initial and follow-up face-to-face sessions to set and monitor individual PA goals. ${ }^{52}$ Likewise, a qualitative study that evaluated participants' perceptions on a weight management intervention during pregnancy concluded that personalised and continued advice on diet and physical activity and supportive approach by goal setting was advantageous in contributing to the success of the intervention. ${ }^{57}$

An RCT conducted among multi-ethnic postpartum women demonstrated that women who received tailored PA recommendations showed a significant increase $(p=0.027)$ in their MVPA levels compared to those who received a generic PA recommendation in the form of a standard PA website access, which might not have provided flexibility and the choice to perform activities convenient to the participants. ${ }^{58}$ Consistent evidence shows that changes in PA are successful in the short term but are not sustainable ${ }^{31,59}$ if they are not tailored to individual needs. ${ }^{59,60}$

Another RCT conducted to examine if theory-based PA consultations would reduce the magnitude of the decline in PA suggests that, for women who are already active at the beginning of pregnancy, simply offering face-to-face PA consultations will not help find adequate alternative activities to engage in during pregnancy, but more intense and tailored interventions are required. ${ }^{32}$ In support of this finding, the included trials ${ }^{52,53}$ used face-to-face PA consultations, along with other experiential and behavioural technique approaches including supervised walking, provision of DVDs to do exercise at home and pedometers as motivational tools. 
The qualitative findings from the study ${ }^{54}$ included in the review show an outright difference from the findings from studies on inactive women. ${ }^{61}$ Previously inactive women reported fewer perceived benefits and greater perceived barriers to leisure-time physical activity during pregnancy compared to the study included in this review. ${ }^{54}$ The study ${ }^{54}$ also captured active women's enthusiasm towards being active and how PA during pregnancy has provided them with confidence and ability to manage a healthy pregnancy and postpartum.

\section{CONCLUSION}

Considering the plethora of health benefits associated with PA during and after pregnancy, health professionals should encourage pregnant and postpartum women to be physically active. It is also vital to prevent the decline of PA levels in already active women during and after pregnancy. This systematic review found that physical activity interventions to support already active pregnant women to remain active during pregnancy are effective. However, this should be interpreted with caution due to the small number of intervention studies in this population. This systematic review also revealed information that would support the design and delivery of interventions such as the type, frequency, mode, method and location of successful PA interventions. The qualitative findings reinforced the enthusiasm among active women to remain active and the benefits they perceive from being active during pregnancy. This review was limited to studies conducted in high-income countries. Similar research in low and middle-income countries are needed. Future research should focus on developing and evaluating a large variety of physical activity interventions that might be suitable among already active women during different phases of pregnancy and postpartum.

\section{Acknowledgements}

We would like to thank Professor Louisa J. Ells for her support during the design of this review.

\section{Disclosure of interests}

None

\section{Contribution to authorship}

MS, LA and PVG contributed to the conceptualisation of the research and developed the protocol for the methodology. MS, LA and LH contributed to data sifting. MS and LA carried out the data extraction, critical appraisal and synthesis. MS drafted the original manuscript and all authors (MS, LH, PVG, LA) contributed to review and editing.

\section{Details of ethics approval}

Not applicable

\section{Funding}

This work was conducted as part of a PhD programme funded by a grant from Sport England

\section{Supporting Information}

Appendix S1. MEDLINE search strategy

Appendix S2. JBI Critical Appraisal Checklist for RCTs

Appendix S3. JBI Critical Appraisal Checklist for Qualitative Studies

Appendix S4. Assessment of Methodological Quality

\section{REFERENCES}

1. Hopkins SA, Cutfield WS. Exercise in pregnancy: weighing up the long-term impact on the next generation. Exercise and sport sciences reviews. 2011;39(3):120-127. 
2. Leite CF, do Nascimento SL, Helmo FR, dos Reis Monteiro MLG, dos Reis MA, Corrêa RRM. An overview of maternal and fetal short and long-term impact of physical activity during pregnancy. Archives of gynecology and obstetrics. 2017;295(2):273-283.

3. Warburton DE, Nicol CW, Bredin SS. Health benefits of physical activity: the evidence. Cmaj. 2006;174(6):801-809.

4. Lee I-M, Shiroma EJ, Lobelo F, et al. Effect of physical inactivity on major non-communicable diseases worldwide: an analysis of burden of disease and life expectancy. The lancet. 2012;380(9838):219-229.

5. Malina RM. Adherence to physical activity from childhood to adulthood: a perspective from tracking studies. Quest.2001;53(3):346-355.

6. Sanabria-Martínez G, García-Hermoso A, Poyatos-León R, González-García A, Sánchez-López M, Martínez-Vizcaíno V. Effects of exercise-based interventions on neonatal outcomes: a meta-analysis of randomized controlled trials. American Journal of Health Promotion. 2015:ajhp. 140718-LIT-140351.

7. Barakat R, Cordero Y, Coteron J, Luaces M, Montejo R. Exercise during pregnancy improves maternal glucose screen at 24-28 weeks: a randomised controlled trial. Br J Sports Med. 2012;46(9):656-661.

8. Juhl M, Andersen PK, Olsen J, et al. Physical exercise during pregnancy and the risk of preterm birth: a study within the Danish National Birth Cohort. American journal of epidemiology.2008;167(7):859-866.

9. Hegaard HK, Pedersen BK, Bruun Nielsen B, Damm P. Leisure time physical activity during pregnancy and impact on gestational diabetes mellitus, pre-eclampsia, preterm delivery and birth weight: a review.Acta obstetricia et gynecologica Scandinavica.2007;86(11):1290-1296.

10. Sorensen TK, Williams MA, Lee I-M, Dashow EE, Thompson ML, Luthy DA. Recreational physical activity during pregnancy and risk of preeclampsia. Hypertension. 2003;41(6):1273-1280.

11. Perales M, Calabria I, Lopez C, Franco E, Coteron J, Barakat R. Regular exercise throughout pregnancy is associated with a shorter first stage of labor. American Journal of Health Promotion.2016;30(3):149-157.

12. Gardner B, Wardle J, Poston L, Croker H. Changing diet and physical activity to reduce gestational weight gain: a meta-analysis. Obesity reviews. 2011;12(7):e602-e620.

13. Streuling I, Beyerlein A, von Kries R. Can gestational weight gain be modified by increasing physical activity and diet counseling? A meta-analysis of interventional trials. The American journal of clinical nutrition. 2010;92(4):678-687.

14. Nordhagen I, Sundgot-Borgen J. Physical activity among pregnant women in relation to pregnancyrelated complaints and symptoms of depression. Tidsskrift for den Norske laegeforening: tidsskrift for praktisk medicin, ny raekke. 2002;122(5):470-474.

15. Devine CM, Bove CF, Olson CM. Continuity and change in women's weight orientations and lifestyle practices through pregnancy and the postpartum period: the influence of life course trajectories and transitional events. Social Science 83 Medicine.2000;50(4):567-582.

16. Slade A, Cohen LJ, Sadler LS, Miller M. The psychology and psychopathology of pregnancy. Handbook of infant mental health.2009;3:22-39.

17. Borodulin K, Evenson KR, Wen F, Herring AH, Benson A. Physical activity patterns during pregnancy. Medicine and science in sports and exercise. 2008;40(11):1901.

18. Evenson KR, Wen F. Prevalence and correlates of objectively measured physical activity and sedentary behavior among US pregnant women. Preventive medicine. 2011;53(1-2):39-43.

19. Brown WJ, Trost SG. Life transitions and changing physical activity patterns in young women. American journal of preventive medicine.2003;25(2):140-143. 
20. Mottola MF. Exercise in the postpartum period: practical applications. Current sports medicine reports. 2002;1(6):362-368.

21. Scholes S, Neave A. Health Survey for England 2016: Physical activity in adults. Health \& Social Care Information Centre Retrieved from http://www hscic gov uk/catalogue/PUB13218/HSE201.2013.

22. Melzer K, Schutz Y, Boulvain M, Kayser B. Physical activity and pregnancy. Sports Medicine. 2010;40(6):493-507.

23. Fell DB, Joseph K, Armson BA, Dodds L. The impact of pregnancy on physical activity level. Maternal and child health journal.2009;13(5):597.

24. Gaston A, Cramp A. Exercise during pregnancy: a review of patterns and determinants. Journal of Science and Medicine in Sport.2011;14(4):299-305.

25. Clarke P, Rousham E, Gross H, Halligan A, Bosio P. Activity patterns and time allocation during pregnancy: a longitudinal study of British women. Annals of Human Biology. 2005;32(3):247-258.

26. Albright CL, Maddock JE, Nigg CR. Physical activity before pregnancy and following childbirth in a multiethnic sample of healthy women in Hawaii. Women \& health. 2006;42(3):95-110.

27. Evenson KR, Aytur SA, Borodulin K. Physical activity beliefs, barriers, and enablers among postpartum women. Journal of women's health. 2009;18(12):1925-1934.

28. Hui AL, Ludwig S, Gardiner P, et al. Community-based exercise and dietary intervention during pregnancy: a pilot study. Canadian Journal of diabetes. 2006;30(2):1-7.

29. Guelinckx I, Devlieger R, Mullie P, Vansant G. Effect of lifestyle intervention on dietary habits, physical activity, and gestational weight gain in obese pregnant women: a randomized controlled trial. The American journal of clinical nutrition. 2010;91(2):373-380.

30. O'Toole ML, Sawicki MA, Artal R. Structured diet and physical activity prevent postpartum weight retention. Journal of Women's Health. 2003;12(10):991-998.

31. Cheung NW, Smith B, van Der Ploeg H, Cinnadaio N, Bauman A. A pilot structured behavioural intervention trial to increase physical activity among women with recent gestational diabetes. Diabetes research and clinical practice. 2011;92(1):e27-e29.

32. Currie S, Sinclair M, Liddle DS, Nevill A, Murphy MH. Application of objective physical activity measurement in an antenatal physical activity consultation intervention: a randomised controlled trial. $B M C$ public health. 2015;15(1):1259.

33. Mailey EL, Hsu W-W. Is a general or specific exercise recommendation more effective for promoting physical activity among postpartum mothers? Journal of health psychology. 2019;24(7):964-978.

34. Callaway LK, Colditz PB, Byrne NM, et al. Prevention of gestational diabetes: feasibility issues for an exercise intervention in obese pregnant women. Diabetes care. 2010;33(7):1457-1459.

35. Jackson RA, Stotland NE, Caughey AB, Gerbert B. Improving diet and exercise in pregnancy with Video Doctor counseling: a randomized trial.Patient education and counseling. 2011;83(2):203-209.

36. Haakstad LA, Bo K. Effect of regular exercise on prevention of excessive weight gain in pregnancy: a randomised controlled trial. The European Journal of Contraception $\&$ Reproductive Health Care. 2011;16(2):116125.

37. Chasan-Taber L, Silveira M, Marcus BH, Braun B, Stanek E, Markenson G. Feasibility and efficacy of a physical activity intervention among pregnant women: the behaviors affecting baby and you (BABY) study. Journal of Physical Activity and Health. 2011;8(s2):S228-S238. 
38. Liu J, Laditka JN, Mayer-Davis EJ, Pate RR. Does physical activity during pregnancy reduce the risk of gestational diabetes among previously inactive women? Birth. 2008;35(3):188-195.

39. Choi J, hyeon Lee J, Vittinghoff E, Fukuoka Y. mHealth physical activity intervention: a randomized pilot study in physically inactive pregnant women. Maternal and child health journal.2016;20(5):1091-1101.

40. Currie S, Sinclair M, Murphy MH, Madden E, Dunwoody L, Liddle D. Reducing the decline in physical activity during pregnancy: a systematic review of behaviour change interventions. PloS one. 2013;8(6).

41. Russo LM, Nobles C, Ertel KA, Chasan-Taber L, Whitcomb BW. Physical activity interventions in pregnancy and risk of gestational diabetes mellitus: a systematic review and meta-analysis. Obstetrics $\mathcal{E}$ Gynecology. 2015;125(3):576-582.

42. da Silva SG, Ricardo LI, Evenson KR, Hallal PC. Leisure-time physical activity in pregnancy and maternal-child health: a systematic review and meta-analysis of randomized controlled trials and cohort studies. Sports medicine. 2017;47(2):295-317.

43. Institute JB. Joanna Briggs Institute reviewers' manual: 2014 edition. Australia: The Joanna Briggs Institute. 2014.

44. Moher D, Liberati A, Tetzlaff J, Altman DG. Preferred reporting items for systematic reviews and meta-analyses: the PRISMA statement.Annals of internal medicine. 2009;151(4):264-269.

45. Subramanian MKP, Ells L, Van der Graaf P, Hayes L, LB A. Effectiveness and perceptions of physical activity interventions in previously active women during pregnancy and postpartum: a mixed-methods review. International Prospective Register for Systematic Reviews (PROSPERO) 2019; https://www.crd.york.ac.uk/prospero/display_record.php?ID=CRD42019119375.

46. Johnson B. 01: THE 2019 UK PHYSICAL ACTIVITY GUIDELINES. 2020.

47. Tufanaru C, Munn Z, Aromataris E, Campbell J, Hopp L. Chapter 3: Systematic reviews of effectiveness. Joanna Briggs Institute Reviewer's Manual 2017; https://reviewersmanual.joannabriggs.org/

48. Lockwood C, Porrit K, Munn Z, et al. Chapter 2: Systematic reviews of qualitative evidence. Joanna Briggs Institute Reviewer's Manual. 2017; https://reviewersmanual.joannabriggs.org/

49. Nordbo ECA, Nordh H, Raanaas RK, Aamodt G. Promoting activity participation and well-being among children and adolescents: a systematic review of neighborhood built-environment determinants. JBI Evidence Synthesis. 2020;18(3):370-458.

50. Institute JB. User Manual for Sumari-System for the Unified Management, Assessment and Review of Information-Version 5.Adelaide, Austrailia. 2013.

51. Lizarondo L, Stern C, Carrier J, et al. Chapter 8: Mixed methods systematic reviews. Joanna Briggs Institute Reviewer's Manual.2017; https://reviewersmanual.joannabriggs.org/.

52. Poston L, Bell R, Croker H, et al. Effect of a behavioural intervention in obese pregnant women (the UPBEAT study): a multicentre, randomised controlled trial. The lancet Diabetes 8 endocrinology. 2015;3(10):767-777.

53. Kennelly MA, Ainscough K, Lindsay KL, et al. Pregnancy exercise and nutrition with smartphone application support: a randomized controlled trial. Obstetrics $\&$ Gynecology. 2018;131(5):818-826.

54. Prewitt-White T, Connolly CP, Feito Y, et al. Breaking barriers: Women's experiences of CrossFit training during pregnancy. Women in Sport and Physical Activity Journal. 2017;26(1):33-42.

55. Williams SL, French DP. What are the most effective intervention techniques for changing physical activity self-efficacy and physical activity behaviour-and are they the same? Health education research. 2011;26(2):308-322. 
56. NICE, Britain G. Four commonly used methods to increase physical activity: brief interventions in primary care, exercise referral schemes, pedometers and community-based exercise programmes for walking and cycling. National Institute for Clinical Excellence; 2006.

57. Atkinson L, Olander EK, French DP. Acceptability of a weight management intervention for pregnant and postpartum women with BMI[?] $30 \mathrm{~kg} / \mathrm{m} \mathrm{2}$ : a qualitative evaluation of an individualized, home-based service. Maternal and child health journal. 2016;20(1):88-96.

58. Albright CL, Steffen AD, Wilkens LR, et al. Effectiveness of a 12-month randomized clinical trial to increase physical activity in multiethnic postpartum women: results from Hawaii's Nā Mikimiki Project.Preventive medicine. 2014;69:214-223.

59. Müller-Riemenschneider F, Reinhold T, Nocon M, Willich SN. Long-term effectiveness of interventions promoting physical activity: a systematic review. Preventive medicine. 2008;47(4):354-368.

60. Rogers LQ, Hopkins-Price P, Vicari S, et al. A randomized trial to increase physical activity in breast cancer survivors. Medicine 85 Science in Sports $\&$ Exercise. 2009;41(4):935-946.

61. Da Costa D, Ireland K. Perceived benefits and barriers to leisure-time physical activity during pregnancy in previously inactive and active women. Women $\& 3$ health. 2013;53(2):185-202.

Table 1 - Participant Characteristics from the included studies

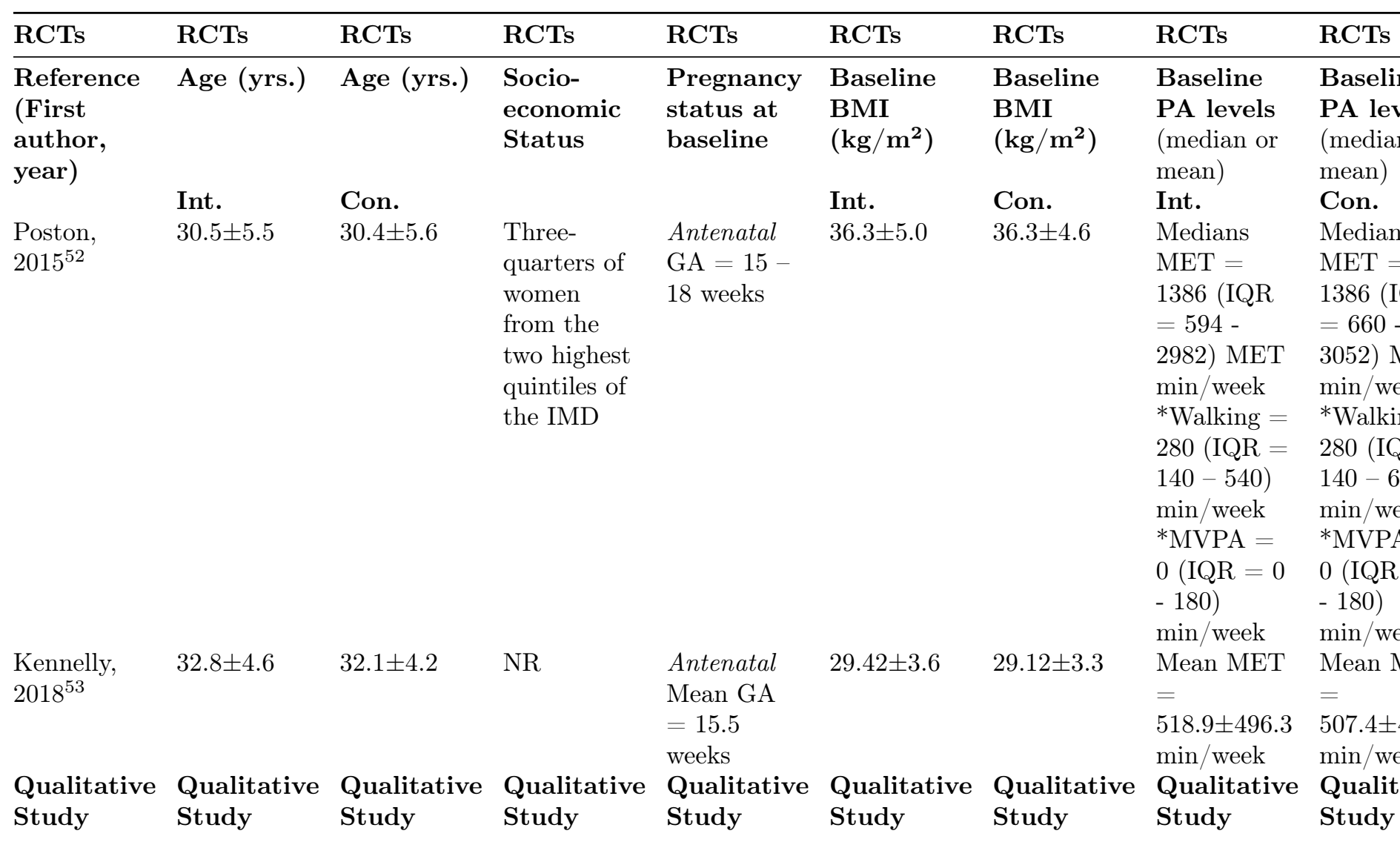




\begin{tabular}{|c|c|c|c|c|c|c|c|c|}
\hline RCTs & RCTs & RCTs & RCTs & RCTs & RCTs & RCTs & RCTs & RCTs \\
\hline $\begin{array}{l}\text { Prewitt- } \\
\text { White, } \\
2017^{54}\end{array}$ & $\begin{array}{l}33 \text { (range } \\
=26-39)\end{array}$ & $\begin{array}{l}33 \text { (range } \\
=26-39)\end{array}$ & NR & $\begin{array}{l}\text { Postpartum } \\
\text { Minimum } 3 \\
\text { months } \\
\text { post- } \\
\text { pregnancy }\end{array}$ & NR & NR & $\begin{array}{l}\text { Minimum } 6 \\
\text { months of } \\
\text { CrossFit } \\
\text { training } \\
\text { throughout } \\
\text { pregnancy }\end{array}$ & $\begin{array}{l}\text { Minim } \\
\text { months } \\
\text { CrossF } \\
\text { trainin } \\
\text { througl } \\
\text { pregna }\end{array}$ \\
\hline
\end{tabular}

GA - Gestational Age; IMD - Index of Multiple Deprivation; MET - Metabolic Equivalent of Task; MVPA - Moderate and Vigorous Physical Activity; IQR - Interquartile Range; NR - Not Reported.

Table 2 - Description of Included Studies 


\begin{tabular}{|c|c|c|c|c|c|c|}
\hline Reference & $\begin{array}{l}\text { Sample } \\
\text { Size } \\
\text { (Baseline) }\end{array}$ & $\begin{array}{l}\text { Intervention } \\
\text { Type \& } \\
\text { Duration }\end{array}$ & $\begin{array}{l}\text { Delivery } \\
\text { Location / } \\
\text { Delivered } \\
\text { By }\end{array}$ & $\begin{array}{l}\text { Frequency } \\
\& \text { Volume } \\
\text { of Inter- } \\
\text { vention }\end{array}$ & $\begin{array}{l}\text { Quantitative } \\
\text { Results } \\
\text { (Change in } \\
\text { PA) }\end{array}$ & $\begin{array}{l}\text { Qualitative } \\
\text { Results }\end{array}$ \\
\hline $\begin{array}{l}\text { Poston, } \\
2015^{52} \text { UK }\end{array}$ & $\begin{array}{l}\mathrm{N}=1555 \\
{[2] \text { Intervention }} \\
\text { Group }=783 \\
{[2] \text { Regular care }} \\
=772\end{array}$ & $\begin{array}{l}\text { Underpinned } \\
\text { by control } \\
\text { theory and } \\
\text { social } \\
\text { cognitive } \\
\text { theory } \\
\text { Individual } \\
\text { interview at } \\
\text { the beginning } \\
\text { of intervention } \\
\text { to set PA goals } \\
\text { [2]Weekly - } \\
\text { Group or } \\
\text { individual } \\
\text { sessions - } \\
\text { SMART goals } \\
\text { assessment, } \\
\text { walking at } \\
\text { moderate } \\
\text { intensity and } \\
\text { other activities } \\
\text { (not specified). } \\
\text { If unable to } \\
\text { attend } \\
\text { instructions } \\
\text { were covered } \\
\text { by telephone. } \\
{[2] \text { Pedometer, }} \\
\text { handbook with } \\
\text { recommended } \\
\text { diet, recipes, } \\
\text { DVD for } \\
\text { antenatal } \\
\text { exercise were } \\
\text { given to the } \\
\text { participants. } 8 \\
\text { weeks. }\end{array}$ & $\begin{array}{l}\text { Trial centre } \\
\text { (hospital } \\
\text { where they } \\
\text { receive } \\
\text { Antenatal } \\
\text { care) Health } \\
\text { trainer }\end{array}$ & $\begin{array}{l}8 \text { sessions over } \\
8 \text { weeks. Each } \\
\text { session }-1 \text { to } \\
1.5 \text { hrs. }\end{array}$ & $\begin{array}{l}\text { Median } \\
\text { difference } \\
\text { (Int/Con) At } \\
27-28 \text { weeks: } \\
\text { MET = } 295 \\
\text { (95\% CI: } 105 \\
\text { to } 485) \text { MET. } \\
\text { min/week } \\
p=0.0015 \\
\text { MVPA }=0 \\
(95 \% \text { CI: }-18 \\
\text { to } 18) \\
\text { min/week } \\
p>0.99 \\
\text { Walking }=77 \\
(95 \% \text { CI: } 28 \text { to } \\
126) \text { min/week } \\
p=0.0018\end{array}$ & NR \\
\hline
\end{tabular}




\begin{tabular}{|c|c|c|c|c|c|c|}
\hline Reference & $\begin{array}{l}\text { Sample } \\
\text { Size } \\
\text { (Baseline) } \\
\end{array}$ & $\begin{array}{l}\text { Intervention } \\
\text { Type \& } \\
\text { Duration }\end{array}$ & $\begin{array}{l}\text { Delivery } \\
\text { Location / } \\
\text { Delivered } \\
\text { By } \\
\end{array}$ & $\begin{array}{l}\text { Frequency } \\
\& \text { Volume } \\
\text { of Inter- } \\
\text { vention }\end{array}$ & $\begin{array}{l}\text { Quantitative } \\
\text { Results } \\
\text { (Change in } \\
\text { PA) }\end{array}$ & $\begin{array}{l}\text { Qualitative } \\
\text { Results }\end{array}$ \\
\hline $\begin{array}{l}\text { Kennelly, } \\
2018^{53} \\
\text { Ireland }\end{array}$ & $\begin{array}{l}\mathrm{N}=565 \\
{[2] \text { Intervention }} \\
\text { group }=278 \\
{[2] \text { Control }} \\
\text { group }=287\end{array}$ & $\begin{array}{l}\text { Face-to-face } \\
\text { educational } \\
\text { session. App } \\
\text { notification } \\
\text { with PA and } \\
\text { diet tips. } \\
\text { E-mail or app } \\
\text { notifications. } \\
\text { Women } \\
\text { enrolled } \\
\text { between } 10 \text { - } \\
15 \text { weeks of } \\
\text { gestation and } \\
\text { measurements } \\
\text { taken at } 28 \\
\text { weeks and } 34 \\
\text { weeks of } \\
\text { gestation }\end{array}$ & $\begin{array}{l}\text { Smartphone } \\
\text { and } \\
\text { face-to-face } \\
\text { visits at } \\
\text { hospital at } 28 \\
\text { and } 34 \text { weeks } \\
\text { of gestation } \\
\text { Research } \\
\text { Team (team } \\
\text { member's } \\
\text { details NR) }\end{array}$ & $\begin{array}{l}\text { One initial } \\
\text { face-to-face } \\
\text { educational } \\
\text { session. } \\
{[2] \text { Daily app }} \\
\text { notification } \\
\text { with PA and } \\
\text { diet tips. } \\
{[2] \text { E-mail or }} \\
\text { app } \\
\text { notification } \\
\text { once every two } \\
\text { weeks. [2]Two } \\
\text { follow up visits } \\
\text { (28 and } 34 \\
\text { weeks). }\end{array}$ & $\begin{array}{l}\text { Mean } \\
\text { difference } \\
\text { (Int/Con) } \\
\text { MET = } 174 \\
(95 \% \text { CI: } 0.04 \\
\text { to } 0.17) \text { MET } \\
p=0.001 \\
\text { adjusted p = } \\
0.02\end{array}$ & NR \\
\hline $\begin{array}{l}\text { Prewitt- } \\
\text { White, } \\
2017^{54} \text { USA }\end{array}$ & $\mathrm{N}=22$ & NA & NA & NA & NA & $\begin{array}{l}\text { The following } \\
\text { themes } \\
\text { emerged from } \\
\text { the interviews: } \\
\text { * Quitting is } \\
\text { not an option } \\
\text { * Sense of } \\
\text { Community } \\
\text { and Support * } \\
\text { Overcoming } \\
\text { judgements } \\
\text { and } \\
\text { stereotyping * } \\
\text { Listening to } \\
\text { my body and } \\
\text { modifying the } \\
\text { movements * } \\
\text { Empowerment } \\
\text { and pride * } \\
\text { Easy } \\
\text { Pregnancy and } \\
\text { delivery * } \\
\text { Lifestyle and } \\
\text { functioning } \\
\text { post-baby }\end{array}$ \\
\hline
\end{tabular}

NR - Not Reported; NA - Not Applicable; MET - Metabolic Equivalent of Task; MVPA - Moderate and Vigorous Physical Activity. 


\section{Hosted file}

Figure 1 - PRISMA Flowchart.docx available at https://authorea.com/users/318083/articles/ 448050-effectiveness-and-perceptions-of-physical-activity-interventions-in-previouslyactive-women-during-pregnancy-and-postpartum-a-mixed-methods-systematic-review 